\title{
EDUARDO NICOL: FILOSOFÍA CIENTÍFICA Y AUTOCOMPRENSIÓN HISTÓRICA
}

\section{EDUARDO NICOL: SCIENTIFIC PHILOSOPHY AND HISTORICAL SELF-KNOWLEDGE}

\author{
Iver A. BeLTRÁN GARCíA* \\ Universidad de Chalcatongo \\ Oaxaca, México
}

\begin{abstract}
Resumen: El artículo se basa en la concepción de Eduardo Nicol sobre el conocimiento, la ciencia, la filosofía y la ideología, y especialmente en un libro de este filósofo, El problema de la filosofía hispánica, para plantear, a través de la interpretación de textos y el análisis de ideas, que en el pensamiento de Nicol la ciencia y la ideología son complementarias respecto al proceso del autoconocimiento humano. En efecto, este proceso, debido a la radical historicidad del ser humano, exige que al conocerse a sí mismo el hombre tome en cuenta a la vez su dimensión universal (su ser en tanto humano) y su dimensión particular (su ser de hombre concreto, histórica y culturalmente situado). El interés, o la philía, aunque determinan que el objeto de la ideología sea lo particular y no lo universal, no la conducen necesariamente a distorsionar o falsear el conocimiento. De tal forma, el artículo abre una vía al diálogo entre quienes conciben a la filosofía como ciencia, y quienes incluyen entre sus notas esenciales el compromiso político o social.
\end{abstract}

\footnotetext{
* Doctor en Filosofía por la Universidad Nacional Autónoma de México (UNAM). Profesor Investigador en la Universidad de Chalcatongo (UNICHA). Líneas de investigación: Antropología filosófica, Filosofía de la cultura e Historia de la Filosofía en México durante el siglo XX. Publicaciones recientes: Beltrán G., Iver A., "Diálogo, comunidad, historia. La teoría de las vocaciones en la metafísica de Eduardo Nicol”, en COMPRENDRE. Revista catalana de filosofia, vol. 19, núm. 1, 2017, pp. 19-37. / Beltrán G., Iver A., "Dialéctica del reconocimiento. Universalidad y particularidad en la filosofía de la historia de Leopoldo Zea”, en THÉMATA. Revista de Filosofía, núm. 55, 2017, pp. 249-266. Correo electrónico: iivehr@hotmail.com
} 
Palabras Clave: Filosofía hispanoamericana, Filosofía española, Filosofía científica, ideología, autoconocimiento.

Aвstract: The article is based on Eduardo Nicol's conception of knowledge, science, philosophy, and ideology, and is especially based on a book by this philosopher, $E l$ problema de la filosofia hispanica. Through the analysis of ideas and the interpretation of texts, and according to Nicol's philosophical thinking, the article argues that science and ideology are complementary in the human self-knowledge process. Because of the radical historicity of the human being, when a man knows himself, he must take into account both his universal dimension (his being as a human being) and his particular dimension (his being as a concrete man, historically and culturally located). Interest, or philia, while determining that the object of ideology is particular and not universal, does not necessarily lead to a distortion of knowledge. Thus, the article opens a way for dialogue between thinkers who conceive of philosophy as a science, and those who include a political or social commitment among the essential features of philosophy.

KeYwords: Hispanic philosophy, Spanish philosophy, scientific philosophy, ideology, self-knowledge.

\section{Introducción}

El pensador hispano-mexicano Eduardo Nicol (Barcelona, 1907-1990) concibió y desarrolló con un carácter estrictamente científico el cuerpo principal de su obra. ${ }^{1}$ Así, por ejemplo, Metafisica de la expresión (1957, 1974), Los principios de la ciencia (1965), La reforma de la filosofía (1980) y Crítica de la razón simbólica. La revolución en la filosofía (1982).

Hay sin embargo entre sus libros un título, El problema de la filosofía hispánica (1961), que Nicol expresamente identifica como una muestra de ideología

\footnotetext{
${ }^{1}$ Husserl influye sobre Nicol en esta forma de entender la filosofía. Sin embargo, la crítica de éste a aquél - - específicamente a su método fenomenológico- es explícita; vid. Nicol, Historicismo y existencialismo, 1950, 23-30; Metafisica de la expresión (primera versión), 1957, 155-210; Los principios de la ciencia, 1965, 294-366; Metafísica de la expresión (segunda versión), 1974, 71-130; La idea del hombre (segunda versión), 1977, 60-83; Crítica de la razón simbólica, 1982, 153-179. Explicaciones adicionales, en Nicol, La vocación humana (1a ed.), 1953, 321-345; Ideas de vario linaje, 1990, 23-37, 47-60, 87-110; y La vocación humana (2a ed.), 1997, 354-380. Para la relación entre Husserl y Nicol, vid. Zirión, 2004, 243-261. Para el sentido de la fenomenología y de la dialéctica en la metafísica de Nicol, vid. Cortés, 2014.
} 
y no de ciencia. Y esto en un sentido radical, pues, como veremos, este filósofo ve entre ideología y ciencia una distinción no meramente formal sino de fondo.

En tal libro Nicol realiza un ejercicio de lo que llamaremos "autocomprensión histórica”, es decir, de conocimiento de sí mismo como filósofo en su concreta dimensión comunitaria e histórica. Revisa diversas etapas de la historia de la filosofía en España e Hispanoamérica; relaciona el decurso del pensamiento filosófico con su contexto económico, político y social; destaca los puntos en que la filosofía, dejando en la sombra su desenvolvimiento como ciencia, ha dado preponderancia a la ideología; y muestra que, no obstante esa preponderancia, la filosofía científica siempre ha formado parte de la historia de las naciones hispánicas, remarcando que en la época en que se escribe el libro dicha filosofía experimenta un crecimiento notable, y que importa impulsar su crecimiento.

Un pensador que entiende y practica la filosofía como ciencia, adopta un pensamiento ideológico para examinar las circunstancias particulares de la filosofía en la comunidad hispánica: este hecho plantea un problema. ${ }^{2}$ ¿Por qué Nicol no efectuó su operación de autoconocimiento a través de una reflexión a la vez filosófica y científica? ¿Por qué fue necesario que adoptara la forma del pensamiento ideológico?

La tesis que sostengo en este artículo es que, de la concepción de la ciencia, de la filosofía y del hombre en la metafísica de Nicol, y de la forma de entender la ideología que este filósofo asume y ejemplifica en El problema de la filosofía hispánica, se infiere que entre ciencia e ideología existe una relación de complementariedad con respecto al proceso de autoconocimiento del ser humano. La ciencia no permite un autoconocimiento del hombre en el nivel de lo particular, y la ideología tampoco en el nivel de lo universal, pero el autoconocimiento del ser radicalmente histórico que es el hombre, para ser completo, tiene que desenvolverse en ambos niveles.

\footnotetext{
${ }^{2}$ Al hacer referencia a la filosofía de Nicol, en vez de ciencia y filosofía puede hablarse de "ciencia-filosofía", puesto que este filósofo concibe a toda ciencia como filosofía, y a la filosofía como ciencia primera. Vid. "El retorno a la metafísica", en Nicol, Ideas de vario linaje, 1990, 23-37; y González V., J., 2009a, 13-26, "La ciencia-filosofía en Eduardo Nicol". Roberto González (2017) efectúa un provechoso contraste entre la concepción nicoliana de la filosofía, marcada por caracteres como la universalidad, la sistematicidad y una actitud vocacional, y la concepción de José Gaos, en la que destacan caracteres como la falta de sistematicidad y de universalidad y una soberbia originaria y fundamental.
} 
Mi método es doble. Primeramente realizo una interpretación de los principales textos de la obra de Nicol para mostrar su concepción del conocimiento, la ciencia, la filosofía y el hombre; pero para esclarecer la relación de complementariedad entre ciencia e ideología, en un segundo momento efectúo un análisis de los conceptos clave. Así, mi tesis queda sólidamente afincada en las ideas de este filósofo, pero a la vez las trasciende, al relacionar sus conceptos de una forma nueva y, a mi parecer, significativa.

Dado que el presente artículo se propone hacer visible un aspecto importante del pensamiento de Nicol, tiene relevancia desde el punto de vista de la historia de la filosofía en Espańa e Hispanoamérica. Pero también posee relevancia con respecto al problema general de la relación entre ciencia, filosofía e ideología. En nuestra época este problema ha estado en el centro de las preocupaciones de múltiples corrientes de pensamiento, como la marxista, la latinoamericanista y la de la liberación; corrientes a las cuales volveremos a referirnos al final del artículo. ${ }^{3}$ Como aporte a la mejor comprensión del problema, el presente trabajo muestra que, si aceptamos elementos básicos de la metafísica de Nicol (como la radical historicidad del ser humano, la universalidad del objeto de la ciencia, y la particularidad del objeto la ideología), estaremos de acuerdo también con la idea de que el ejercicio de la ideología complementa el de la ciencia en el proceso de autoconocimiento del hombre.

En la sección 2 haré una síntesis de la concepción de la filosofía en la obra de Nicol, destacando los conceptos de praxis, conocimiento, ciencia, opinión y filosofía científica. En la sección 3 explicaré el sentido y las ideas principales de $E l$ problema de la filosofía hispánica, así como las notas mediante las cuales el autor caracteriza en este libro al pensamiento ideológico. En la sección 4 desenvolveré mi tesis de la complementariedad entre ciencia e ideología, y para evitar malos entendidos, propondré hablar de "autocomprensión histórica" en vez de ideología, si comprendemos a esta última de la misma forma que Nicol.

\footnotetext{
${ }^{3}$ Pensemos, por ejemplo, en "Filosofía, ideología y sociedad" del marxista Adolfo Sánchez Vázquez (2003b, 254-279); y en "Del concepto de ideología” del pensador Luis Villoro, que pone el análisis filosófico al servicio de la tarea liberadora (2007, 15-37).
} 


\section{Ciencia y opinión en la obra de Nicol}

Nicol describe a la "praxis" como actividad humana en tanto humana, en general, a diferencia de otros pensadores para quienes la praxis se restringe a una forma específica de la actividad humana; por ejemplo, resalta el contraste con el marxista Adolfo Sánchez Vázquez en su Filosofía de la praxis, donde la praxis, en el sentido de actividad práctica, implica la transformación efectiva de un objeto "material”, "real”, “objetivo" (cfr. Sánchez Vázquez, 2003a, 270-271). ${ }^{4}$

Todos los niveles y formas de la praxis comparten sus factores, sus elementos, sus componentes y sus relaciones. En seguida explicaré esto de forma breve, con el fin de destacar posteriormente aquello que distingue a la ciencia o episteme respecto a los otros niveles y las otras formas de la praxis, y especialmente, respecto a la doxa u opinión precientífica, de la cual la ideología constituye una forma.

Nicol considera factores de la praxis a la necesidad, la libertad y el azar. En toda praxis intervienen lo que no puede ser y lo que no puede no ser (las dos caras de la necesidad), lo que puede ser (elemento de la libertad), y lo que, como producto de la necesidad o de la libertad, se presenta como imprevisto, como inesperado (azar). Necesidad y libertad se relacionan dialécticamente, pues los límites de lo necesario marcan el espacio abierto a lo posible, y constituyen regímenes, cada uno con su propia legalidad distintiva. El azar, en cambio, no representa una tercera forma de legalidad, un tercer régimen, pues consiste en el

\footnotetext{
${ }^{4}$ Nicol desarrolla a lo largo de su obra diferentes aspectos del concepto de praxis, que en su pensamiento ocupa un lugar central. La importancia de las relaciones del ser del hombre con su entorno y consigo mismo: Nicol, Psicología de las situaciones vitales, 1941, 59-92 y 121 165; El problema de la filosofía hispánica, 1963, 71-89 y 108-135. La idea del ser del hombre como potencialidad espiritual: Nicol, La idea del hombre (primera versión), 1946, 28-32. La vocación humana como "ser más": Nicol, La vocación humana (1a ed.), 1953, 25-45; La vocación humana (2a ed.), 1997, 35-57. Vocación humana y vocaciones particulares: Nicol, 1953, 9-21; 1997, 19-32. El ser del hombre como expresión: Metafísica de la expresión (primera versión), 1957, 273-284, 375-413; Metafísica de la expresión (segunda versión), 1974, 176-179, 227-281. Las vocaciones particulares como disposiciones o actitudes ante el ser: Nicol, 1957, 375-386; 1974, 249-257. Causalidad natural y causalidad histórica: Nicol, Los principios de la ciencia, 1965, 189-293. La crisis contemporánea de la praxis: Nicol, El porvenir de la filosofía, 1972, 61-75; La agonia de Proteo, 2004, 123-132; La reforma de la filosofía, 1980, 244-295. Los factores de la praxis: Nicol, La idea del hombre (segunda versión), 1977, 11-109. Praxis "práctica" y praxis "im-práctica": Nicol, La primera teoría de la praxis, 1978, 11; 1965, 281-282. El principio vocacional: Nicol, Crítica de la razón simbólica, 1982, 140150. En González V., J., 2009b, la autora ubica la ontología del hombre elaborada por Nicol, con respecto al proyecto metafísico de este mismo filósofo.
} 
cruce inopinado de dos o más líneas causales que pueden pertenecer al orden de la necesidad o al orden de la libertad. ${ }^{5}$

En cuanto a los elementos de la praxis, en Metafísica de la expresión este filósofo describe al ser y hacer del hombre, así como a los productos de ese hacer, como fenómenos expresivos: "el hombre siempre expresa" y "todo en el hombre es expresivo" (Nicol, 1974, 142); de ahí que los elementos de la expresión sean, a la vez, elementos de la praxis. Nicol distingue cuatro elementos ( $c f r$. Nicol, 1957, 375-414; 1974, 249-281):

- Primer elemento: El objeto. Todo fenómeno expresivo incluye siempre una manifestación del ser del objeto.

- Segundo elemento: El sistema simbólico. El ser del objeto sólo se manifiesta a través de un determinado sistema de símbolos.

- Elementos tercero y cuarto: El sujeto y el interlocutor efectivo o virtual. El conocimiento no se reduce a la relación del sujeto con el objeto, sino que implica la relación del sujeto con un interlocutor. ${ }^{6}$ Esto se debe a que la base del conocimiento es la objetivación del ser que se manifiesta ante el sujeto. Tal objetivación consiste en la interpretación del ser manifestado, a través de una malla de relaciones que asemeja o distingue ese ser respecto a otros objetos y que, por tanto, nos permite clasificarlo y particularizarlo. ${ }^{7}$ Esa

\footnotetext{
${ }^{5}$ El tema de los factores de la acción, considerados como destino, azar y carácter, aparece en Psicología de las situaciones vitales (vid. 1941, 167-208; 1963, 136-162). La Metafísica de la expresión conceptúa esos factores, en términos ontológicos, respectivamente como necesidad, contingencia y libertad (cfr. Nicol, 1957, 316-320; 1974, 201-204). Pero es la segunda versión de La idea del hombre la que en su primera parte desarrolla prolijamente el análisis de tales factores, precisando: (i) que el azar es contingencia en su forma adventicia y externa (pues la contingencia constitutiva e interna es la propia del hombre y se identifica con su libertad); (ii) que el destino es la necesidad interna y externa (por ejemplo, la naturaleza es necesidad externa para el ser del hombre, pero la libertad es su necesidad interna, en tanto el hombre es necesariamente libre); y (iii) que el carácter es un producto de la libertad: "la obra del hombre consigo mismo" (Nicol, 1977, 30; cfr. 11-109). Crítica de la razón simbólica define el destino como "lo dado", el azar como "lo inevitable inopinado", y la libertad como "la manera regular e in-necesaria de enfrentarse a la necesidad" (cfr. Nicol, 1982, 89-94).

${ }^{6}$ El tema del diálogo como condición de posibilidad del conocimiento, es desarrollado por Nicol en Metafísica del conocimiento (Nicol, 1957, 284-293; 1974, 179-185), Los principios de la ciencia (Nicol, 1965, 61-80) y Crítica de la razón simbólica (Nicol, 1982, 50-56).

7 "El entendimiento es una función hermenéutica, que quiere decir dialógica" (Nicol, Metafísica de la expresión, 1974, 182). "[...] el conocimiento de un objeto real nuevo es de hecho
} 
malla de relaciones, cuando es coherente y cristaliza en una estructura, es lo que Nicol llama sistema de símbolos, o en general, lenguaje. ${ }^{8}$ Pues bien, los sistemas de símbolos o lenguajes, que configuran los objetos en el mundo y el mundo mismo, al estar siempre situados en una determinada evolución histórica y en una concreta comunidad, son productos del diálogo del sujeto con otro sujeto. ${ }^{9}$ El diálogo consiste en la reinterpretación del mundo y de los objetos en el mundo con base en las interpretaciones previas y a partir de la propia captación de los seres que se manifiestan. ${ }^{10}$

Respecto a los componentes de la expresión y de la praxis, Nicol distingue uno de manifestación del ser, o apófansis, y uno de simbolización, o póiesis. ${ }^{11} \mathrm{La}$ apófansis corresponde en la expresión a lo dado al sujeto; la póiesis, a lo puesto por el sujeto, a la interpretación que éste efectúa de lo manifestado. Todo conocimiento resulta subjetivo e histórico por su componente poiético, es decir, por la evolución de sus sistemas simbólicos, pero a la vez posee objetividad, debido a su componente apofántico, la manifestación del ser que subyace a esos sistemas simbólicos. ${ }^{12}$

En Los principios de la ciencia Nicol explica que los indicados elementos de la expresión se enlazan entre sí a través de cuatro relaciones: la epistemológica, que vincula sujeto y objeto; la dialógica, correspondiente a la liga de sujeto e interlocutor; y la lógica y la histórica, ambas entre símbolos, pero de modo que la

ya un auténtico reconocimiento: lo identificamos, no por su propia individualidad óntica, la cual nos era desconocida, sino en relación con otros entes conocidos ya” (Nicol, 1974, 111). 8 "[...] sin cooperación de los símbolos no puede formarse o articularse pensamiento alguno" (Nicol, Los principios de la ciencia, 1965, 62).

9 Para la historicidad de los sistemas simbólicos, vid. Nicol, Los principios de la ciencia, 1965, 50-61. Para la relación entre sistemas de símbolos y comunidad, vid. Nicol, Metafísica de la expresión (primera versión), 1957, 381-386; Metafísica de la expresión (segunda versión), 1974, 252-257.

10 "Todo acto es expresivo y tiene sentido, toda interpretación es un acto; de suerte que cualquier expresión anticipa el acto ajeno que lo haga objeto de una interpretación, y ésta contiene virtualmente la interpretación consiguiente con que prosigue el diálogo" (Nicol, 1974, 219-220).

${ }^{11}$ Para el tema de la apófansis y la póiesis, vid. Metafísica de la expresión (Nicol, 1957, 273284; 1974, 176-179), y Los principios de la ciencia (Nicol, 1965, 68-80).

12 "[...] la representación es una creación en la cual, a pesar de ser un acto subjetivo, con todo lo que esto implica, se hace patente una realidad objetiva” (Nicol, 1965, 77). 
primera abstrae la evolución de los símbolos en el tiempo, y la segunda reintegra los mismos a su evolución histórica concreta.

Todos los niveles y formas de la praxis comparten, pues, factores, elementos, componentes y relaciones. A partir de esto, Nicol distingue los niveles de la praxis tomando en cuenta dos criterios, el de su relación con la utilidad y el de su relación con la verdad. Conforme a su relación con la utilidad, el primer nivel es la praxis "práctica", y el segundo, la praxis "im-práctica"; respecto a su relación con la verdad, la praxis presenta tres niveles: la representación, la opinión precientífica (doxa) y la opinión científica (episteme).

Veamos primeramente los niveles de la praxis por su relación con la utilidad.

En La reforma de la filosofía (1980, 114-124), Nicol observa lo siguiente: a pesar de que la relación entre la necesidad y la libertad es, ella misma, necesaria, el hombre puede superar la necesidad: "Lo que pudiera llamarse liberación de lo forzoso consiste en la producción, por medios naturales o físicos, y con el concurso de las causas necesarias, de algo que la naturaleza no depara por sí sola" (ibid., 123). La acción humana, con la intervención de la naturaleza, crea mundos distintos al natural y no explicables sólo por la causalidad natural. Por ejemplo, el mundo de los instrumentos que facilitan o mejoran la satisfacción de las necesidades naturales, y el mundo de los instrumentos que sirven para producir otros instrumentos. Pero la acción humana también crea productos cuyo sentido y valor no radica en la utilidad: "Un nivel más alto en la superación se alcanza cuando el acto es literalmente in-necesario, prácticamente in-útil” ( $i d$.), como en el arte, en la poesía y en la filosofía. Aquí Nicol, que habla de la filosofía en el sentido de ciencia en general, se refiere al paso del nivel de lo útil, de lo práctico, al nivel de lo "in-útil”, lo "im-práctico". ${ }^{13}$

En este último nivel existen diversas formas de la praxis, de conocimiento o expresión, que este filósofo llama también vocaciones, y que concibe como disposiciones o actitudes ante el ser. ${ }^{14}$ Por ejemplo, el arte, la poesía y la ciencia:

\footnotetext{
${ }^{13}$ En este sentido habla Nicol de la "inutilidad esencial de la filosofía" (1980, 193).

${ }^{14}$ En La primera teoría de la praxis, Nicol explica que sólo son posibles tres dispositivos "imprácticos", o disposiciones desinteresadas ante el ser: "el teórico, el místico y el estético" $(1978,63)$. A estos dispositivos podemos propiamente llamarlos formas de la praxis "impráctica”. La praxis "práctica” tiene sus propias formas, como la economía y la política. Se trata de formas simbólicas, cada una con su propia unidad de sentido y con una base de principios distintivos (cfr. Nicol, Metafísica de la expresión, primera versión, 1957, 364-374;
} 
ninguna de ellas puede plantearse la utilidad como objetivo genuino, originario. $\mathrm{El}$ interés les es ajeno; el "desinterés" constituye su marca fundamental. ${ }^{15} \mathrm{Se}$ pueden utilizar sus productos, sus resultados; pero la aplicación se da de manera exterior, contingente, no esencial.

Tal desinterés, por tanto, aparece como característica necesaria en la descripción que Nicol hace de la ciencia. Así, este filósofo escribe en La idea del hombre:

[...] el ser es lo dado, cualesquiera que sean mis intenciones o disposiciones. Sin embargo, cuando lo apreso como objeto útil no me preocupo de su mismidad, ni me percato siquiera de que haya otras formas de captarlo. La praxis no lo oculta: nada puede ocultarlo. Lo que hace la praxis es descuidarlo, en cuanto a su ser, por cuidad nada más de su aparente utilidad (Nicol, 1977, 301). ${ }^{16}$

La utilidad, el "ser para mí", es una apariencia que el interés del sujeto, al descuidar el ser del objeto, proyecta sobre éste. El "ser en sî", en cambio, se muestra gracias al cuidado del ser, un cuidado que consiste precisamente en librar al objeto de todas las apariencias proyectadas por el sujeto (prejuicios, errores, intereses) y que encubren su ser. ${ }^{17} \mathrm{La}$ ciencia, por principio, cuida del ser de las cosas, y por ello mismo no puede cuidarse de su utilidad, no puede ser interesada.

El cuidado del ser es distintivo de la ciencia, se manifiesta formalmente por el método, y explica otras características, como la actitud crítica y la búsqueda de universalidad (en el doble sentido de ocuparse de un objeto universal y de

Metafísica de la expresión, segunda versión, 1974, 240-248; La reforma de la filosofía, 1980, 135-158). González, Rush, 2007, analiza en la filosofía de Nicol la dimensión sapiencial y vocacional de la ciencia.

15 "Interés" no en el sentido de atención, sino como búsqueda de provecho, de rendimiento, de utilidad.

${ }^{16}$ Cfr. el pasaje entero: Nicol, 1977, 295-302.

${ }^{17}$ El "en sí" del ser es entendido por Nicol, no como identidad atemporal, sino como "mismidad” fenoménica (cfr. Nicol, 1974, 113-114). 
afanarse por una validez universal). Ese cuidado también hace diferente a la ciencia, o episteme, respecto a la opinión precientífica, o doxa. ${ }^{18}$

La ciencia o episteme, según el criterio de la relación de la praxis con la utilidad, pertenece por tanto al segundo nivel, el de la praxis desinteresada, "impráctica”, y dentro de este nivel se distingue por su disposición de cuidado ante el ser.

Veamos ahora los niveles de la praxis por su relación con la verdad.

El primero de estos niveles es el de la representación, esto es, la interpretación de un ser "como algo real, patente y presente" (Nicol, 1965, 70); una interpretación que opera inclusive en el gesto indicativo y en el pronombre demostrativo, pero que adopta su forma más acabada en el concepto, al cual Nicol entiende como "un juicio concentrado, comprimido o abreviado" (ibid. 71), y por tanto, portador de verdad. ${ }^{19}$

El segundo nivel corresponde a la opinión precientífica o doxa. En la opinión en general, a diferencia de la representación, el sujeto no sólo expresa la presencia y la realidad del objeto, sino que toma posición respecto a "el qué, el cómo, el por qué y el para qué del objeto" (ibíd. 82).

En este segundo nivel, tal posición está determinada por la subjetividad del sujeto. En cambio, en el tercer nivel, que es el de la opinión científica y que también efectúa una posición, lo que prevalece es el cuidado del sujeto por el ser del objeto (cfr. ibid. 42-47).

Como vemos, la ciencia o episteme se localiza en diferentes niveles de la praxis, dependiendo del criterio que se toma como base: la relación de la praxis con la utilidad, o la de la misma con la verdad. Pero en ambos casos la nota distintiva de la ciencia es el cuidado por el ser, del cual, como ya se indicó, derivan sus

\footnotetext{
${ }_{18}$ Para la distinción entre doxa y episteme, vid. Metafísica de la expresión (Nicol, 1957, 291293; 1974, 184-185) y Los principios de la ciencia (Nicol, 1965, 42-46).

${ }_{19}^{19}$ Para los niveles del conocimiento y de la verdad, vid. Nicol, 1965, 68-93; 1957, 277; 1974, 177. "El símbolo 'mesa', con el cual se representa conceptualmente un determinado objeto, concentra toda una serie de relaciones simbólicas que pretenden ser verdaderas, a saber: la afirmación de la realidad objetiva de tal cosa; su distinción respecto de otra cosa, como es la silla; la pertenencia de ambas a un género común, que es el género mueble; la distinción entre este género y los otros objetos de géneros distintos, etcétera” (Nicol, 1965, 72).
} 
caracteres formales, como la crítica, el método y la universalidad. Por ello, a esta disposición o actitud vocacional ante el ser Nicol la considera como uno de los principios o fundamentos de la ciencia, a saber, el vocacional (cfr. 1982, 140-150).

Así como la praxis tiene sus niveles, los tiene también la ciencia, cuya estructura Nicol describe en forma de pirámide $(1965,80-89) .{ }^{20}$

El primer nivel de la pirámide de la ciencia es el de las evidencias o principios, que se encuentran ya en la experiencia primaria y común, pero que sólo el cuidado del ser libera y formula. En el segundo Nicol sitúa la recolección de datos. En el tercer nivel se relacionan los datos para formar leyes, y las leyes para formar teorías. Hay pues una gradación, desde el nivel del conocimiento más apofántico, menos dependiente de las interpretaciones subjetivas, hasta el nivel más poiético, el menos apegado a las evidencias empíricas.

En el análisis de Nicol, el primer nivel, el más apofántico, que constituye la base de la pirámide y por tanto de la ciencia en su conjunto, es el de la metafísica, ciencia primera, sistema de los principios de la ontología y la epistemología. La metafísica no sólo es ciencia, sino que además es la ciencia menos especulativa, es decir, la menos poiética, la que menos interpreta el ser manifestado, la menos sujeta a las variaciones históricas de los sistemas simbólicos.

Tal idea de la metafísica es el resultado de la crítica que este filósofo opera sobre la principal tradición de la historia de la filosofía en Occidente, tradición que Nicol llama "parmenídea" y que se basa en el supuesto de la intemporalidad del ser y de la ahistoricidad de la verdad (cfr. Nicol, 1957, 141-210; 1974, 71-130; 1965, 294-366; 1982, 153-219). ${ }^{21}$ Conforme a tal presupuesto, la metafísica buscaba al ser más allá de lo "físico", es decir, más allá de la realidad cambiante que captan nuestros sentidos, en una experiencia especial en la que el pensamiento - depurado metódicamente de la experiencia primaria y común- parecía tener la capacidad de separar realidad y ser, historia y verdad. Nicol opone a la tradición parmenídea la evidencia de que "el ser está a la vista"

\footnotetext{
${ }^{20} \mathrm{Al}$ examinar los niveles de esa pirámide, tengamos presente que la filosofía científica es entendida por este pensador en dos sentidos: como ciencia sin más o episteme (ciencia-filosofía), y como metafísica o ciencia primera.

${ }^{21}$ Especialmente importante para este tema, además de los lugares referidos, es el texto "El absoluto negativo", en Nicol, Ideas de vario linaje, 1990, 47-60. Roberto González (2014) desarrolla este tema.
} 
(Nicol, 1950, 34; 1974, 102), es decir, la de que el ser se muestra en los entes, y por tanto es temporal, como histórica es la verdad: "ser y realidad son uno y lo mismo" (Nicol, 1974, 99; cfr. ibid., 126, y 1977, 72). ${ }^{22}$ Con base en esa crítica es que Nicol considera que la metafísica se localiza en el primer nivel de la ciencia, el más apegado a las evidencias de la experiencia primaria y común.

Entre dichas evidencias — objeto de la ciencia metafísica - están las que Nicol identifica como principios de la ciencia: la unidad y comunidad de lo real, la unidad y comunidad de la razón, la racionalidad de lo real y la temporalidad de lo real (cfr. Nicol, 1965, 369-510; 1982, 119-150). Se trata de verdades a la vez fácticas y necesarias, en el sentido de objetivas y evidentes. De acuerdo con tales principios, en la experiencia primaria y común todos los entes se nos muestran en movimiento (temporalidad de lo real), pero siempre con un orden (racionalidad de lo real), y a cada uno de ellos podemos hacerlo objeto de nuestra experiencia, de nuestro conocimiento, lo cual significa que constituye un referencial común (unidad y comunidad de lo real) entre sujetos con la misma capacidad de remitirse a ese objeto los unos a los otros a través de algún sistema simbólico (unidad y comunidad de la razón).

En lo dicho en esta sección vemos, pues, que todos los niveles y las formas de la praxis comparten factores (necesidad, azar y libertad), elementos (sujeto, interlocutor, objeto, sistema simbólico), componentes (apofántico, poiético), y relaciones (epistemológica, dialógica, lógica e histórica). Un nivel, el de la praxis "im-práctica", que corresponde al arte, la poesía y la ciencia, se caracteriza por su desinterés. Y la ciencia, a su vez, se distingue de las otras formas de la praxis "im-práctica", así como de la doxa, de la opinión precientífica, por su particular disposición o actitud, que es la del cuidado del ser (principio vocacional), de la cual se desprenden otros caracteres, como la crítica, el método y la universalidad.

Tal es la concepción de la ciencia que fundamenta el pensamiento filosófico de Nicol y atraviesa ese pensamiento de principio a fin. En este marco es que habremos de situar su libro El problema de la filosofía hispánica, así como su caracterización de la ideología.

\footnotetext{
${ }^{22}$ Vid. Horneffer, 2013, 65-78: "[...] si el ser no se identifica con nada en particular, pero al mismo tiempo aparece en todo aquello que es, entonces es necesario determinar la diferencia, que no se encuentra en un nivel puramente lógico sino más bien en uno rigurosamente ontológico-fenomenológico" (72).
} 


\section{El problema de la filosofía hispánica: la filosofía como ideología}

Entre 1959 y 1960 impartió Nicol dos conferencias en la Columbia University de Nueva York y en la Université Libre de Bruselas, conferencias que aprovechó para redactar el texto "El problema de la filosofía hispánica" (cfr. Nicol, 1998, 21). Este texto fue incluido por su autor como primera parte en el libro del mismo nombre; una segunda y tercera parte, escritas ex profeso para el libro, se titulan respectivamente "La escuela de Barcelona" y "Ensayo sobre el ensayo" (cfr. id.).

En la primera parte del libro, pues, llamada como el libro en su conjunto, Nicol, como ya he indicado, efectúa una interpretación de la historia de la filosofía en Hispanoamérica. Para comprender esa interpretación, es necesario familiarizarnos con la diferencia que este filósofo hace entre el tipo científico y el tipo ideológico de la filosofía.

De la filosofía como ciencia ya vimos que se refiere a una forma de la praxis que destaca por su desinterés, como el arte y la poesía, pero que a diferencia de éstas y de la doxa u opinión precientífica, se funda en una disposición o actitud de cuidado del ser, es decir, en un afán por desembarazar el ser de la capa de errores, prejuicios e intereses que ocultan o distorsionan su manifestación.

Pues bien, en El problema de la filosofía hispánica Nicol observa que la filosofía científica no es la única forma de hacer filosofía. Frente a la filosofía científica, que constituye el estilo central y principal, están los estilos marginales (que, sin embargo, llegan a predominar históricamente en ciertas situaciones): la ideología, la sofística, los sistemas inventados, las ideas sueltas (cfr. ibid. 36-44). ${ }^{23}$ Los estilos marginales no son formas de expresión a través de las cuales pudieran llegar a expresarse lo mismo la episteme que la doxa; son, sí, formas de expresión, pero sólo de la doxa, de la opinión precientífica (cfr. ibid. 45). La ideología, específicamente, consiste en un sistema de ideas, de opiniones precientíficas o doxai, y refiriéndose a ella observa Nicol: "Toda la filosofía política es ideología. La pedagogía, los sistemas de doctrina pedagógica, tampoco son otra cosa que ideología" (ibid. 42). La filosofía política y la pedagogía, en el análisis de Nicol, tienen carácter de opiniones no científicas.

${ }^{23}$ Comparar con Nicol, Los principios de la ciencia, 1965, 84-85. 
Esto se debe a que la ideología tiene como base el interés o la philía hacia la propia comunidad. De ello habla Nicol cuando dice en la primera parte de El problema de la filosofía hispánica: "estas disquisiciones sobre la filosofía hispánica no pueden ser otra cosa que 'ideología'. Esto no es ciencia”; y añade: "no deben otorgar a mis opiniones la misma autoridad que siempre poseen las teorías científicas" (ibid. 45). Pues las opiniones que vierte este filósofo en su texto, aunque son inspiradas "por una philía de la verdad", complican este amor "con otra suerte de philia o filiación que no permite ser tan desinteresado", es decir, "la afiliación a esos países de la comunidad hispánica [...] la participación en los esfuerzos que hacen por encontrarse a sí mismos, por conocer y regular sus destinos" $(i d.) .{ }^{24}$

Las opiniones de Nicol en su libro no distorsionan la verdad por mor de satisfacer un determinado interés (las inspira una "philía de la verdad"), pero tampoco cumplen una característica esencial de la filosofía científica, la universalidad de su objeto; pues, en efecto, la filosofía

ex-pone el ser: pro-pone verdades hablando del ser tal como es en sí mismo. Esta proposición es universal en dos sentidos. Primero: lo que se dice del ser abarca a todo ente; lo que se dice del ser de un ente se dice de todo ente de la misma familia. Y segundo: la verdad tampoco es restrictiva de cara a los hombres. Por su naturaleza misma, la proposición de la verdad es un acto de apertura que deja al ser en posición asequible, o sea ex-puesto ante cualquiera que, a su vez, esté dis-puesto a participar en él verdaderamente (Nicol, 1980, 218).

\footnotetext{
${ }^{24}$ Nicol parece hacer referencia a una philía que conlleva interés. Pero esto no es así. En la filosofía de Nicol el amor y el interés son entendidos como principios de conducta opuestos y excluyentes. El interés se asocia al afán de poder, a la praxis económica y política, mientras que el amor está vinculado al afán de servicio, a las actividades vocacionales. Vid., por ejemplo, Nicol, La vocación humana (2a ed.), 1997, "El sueño del poder" y "El saber y el poder", 293-295, 296-298; El porvenir de la filosofía, 1972, 15-24; y La primera teoría de la praxis, 1978, 15-26. Para no introducir una discordancia en el pensamiento de este filósofo, hay que interpretar — como queda señalado_ que la ideología puede ser promovida por el interés y también, adicionalmente, por la philia hacia la propia comunidad.
} 
La universalidad filosófica se entiende como búsqueda de validez universal (segundo sentido), pero primeramente en el sentido de que su objeto de estudio es universal. Así, lo que al filósofo le corresponde no es pensar en el ser del español, o del mexicano, o de cualquier comunidad particular, sino pensar en el ser del hombre sin más. En cambio, lo que Nicol hace en El problema de la filosofía hispánica es dirigir su pensamiento precisamente a una comunidad particular, la hispánica, en la que incluye a España, y ello debido a que, junto con la "philía de la verdad", lo mueve la philía a esa comunidad: "A veces hay motivaciones legitimas, apremiantes, para pensar los problemas de nuestra vida, y no los de la vida en general; los de nuestra comunidad, y no los de la comunidad en general; los de nuestro ser y hacer, y no los del ser y el hacer en general' (Nicol, 1961, 43-44). ${ }^{25}$

La ciencia o episteme, conforme a lo dicho, se caracteriza por ser desinteresada y por su universalidad, mientras que la ideología, como una forma de doxa, está marcada por el interés (o la philía hacia la comunidad concreta) y por la particularidad de su objeto. Entre una y otra existe una relación de oposición, no de contradicción: lo universal se opone a lo particular, el interés al desinterés, pero en lo particular puede confirmarse lo universal (en el ser del mexicano o del español se realiza la forma común del ser humano), así como el interés de la ideología puede hacer uso de los resultados de la ciencia desinteresada, sin necesariamente falsearlos o distorsionarlos (así Nicol en El problema de la filosofía hispánica, utilizando su universal concepción del hombre, de la ciencia y de la filosofía al estudio de la particular comunidad hispánica). ${ }^{26}$

\footnotetext{
${ }^{25}$ Las cursivas son mías.

${ }^{26}$ Conforme a lo dicho, en el marco de la filosofía de Nicol la historia - el conocimiento del hombre en su concreto y particular devenir histórico- , como toda ciencia, tiene como base el cuidado del ser, y por tanto, está determinada por el método y la búsqueda de objetividad y universalidad. Su tema, más que el cambio en sí mismo, es la forma del cambio, la ley del cambio. Así, por ejemplo, cuando Nicol se ocupa de la historia de Grecia (en las dos versiones de La idea del hombre, y en La primera teoría de la praxis), a la vez que hace historia, hace sistema; es decir, su pensamiento se dirige a las regularidades de esa historia que nos hablan del hombre sin más y no sólo del hombre griego. Sobre tal tema, vid. Nicol, Metafísica de la expresión, 1974, 12; Crítica de la razón simbólica, 1982, 103-116. Cuando este filósofo habla de la ideología, en tanto conocimiento de lo concreto y particular, no hace referencia al conocimiento propio de la ciencia histórica: "La filosofía de la historia no puede adoptar como sujeto, o tema de su estudio, las historias nacionales, y menos aún las biografías de personajes políticos: ha de ser filosofía de la historia universal. Sin esta universalidad no podría ser científica [...]" (Nicol, Los principios de la ciencia, 1965, 291). Nicol no deja lugar para confundir la historia, como ciencia, y la ideología, como conocimiento precientífico.
} 
Haciendo, pues, ideología en este sentido, Nicol en dicho libro interpreta la historia de la filosofía hispanoamericana distinguiendo sus etapas con base en el predominio que tuvo en ellas el tipo ideológico o el tipo científico de la filosofía (ibid. 46).

En la primera etapa prevalece el ethos de la Independencia ( $c f r$. Nicol, 1961, 45-56). "Ethos", en la filosofía de Nicol, se refiere a la disposición o actitud que el hombre adopta ante el ser como forma auténtica de realizar su humanidad; por ejemplo, el ethos de la ciencia — que es un ethos vocacional- radica en su cuidado del ser: sin tal disposición, el ejercicio de la ciencia carece de autenticidad (cfr. Nicol, 1980, "La génesis de la filosofía" y "Ontología de la filosofía", pp. 159-217). ${ }^{27}$ En el caso de las naciones de Hispanoamérica, lo que Nicol quiere decir es que en el siglo XIX las relaciones entre sus hombres, y las de sus hombres con los de otras naciones y con la realidad en su conjunto, estuvieron presididas por la Independencia como idea y como ideal de vida colectiva. ${ }^{28}$ Los hispanoamericanos centraron su pensamiento en la idea de Independencia en la medida que la Independencia era la guía en la construcción de su ser colectivo. De la misma manera, ya a fines de ese mismo siglo y hasta mediados del siguiente, el ethos de la Independencia fue sucedido por el ethos de la Revolución ( $c f r$. Nicol, 1998, 56-109), a cuyo filosofar Nicol llama específicamente "meditación del propio ser"; ethos, el de la Revolución, que no ha de entenderse en el sentido de un corte abrupto y un cambio de rumbo, sino como radicalización en el plano económico, social y filosófico, respecto a lo que la etapa anterior había propuesto y había logrado en el plano político y en el aspecto del pensamiento.

\footnotetext{
27 Sobre el sentido del término ethos en la ontología de Nicol, vid. Nicol, 1957, 375-386; 1974, 249-257; 1982, 145-150, y El problema de la filosofía hispánica, 1998, 21-26. También se consultará con provecho González y Sagols, 2002, 7-17 y 223-227. Nicol, como Ortega y Gasset, distingue el concepto de ethos respecto al de ética y al de moral, y en estrecha vinculación al de vocación. Para Nicol, el marco y la base del ethos es el ser del hombre como ente expresivo y vocacional (cfr. Nicol, 1974, 217-224, y 1982, 145-150); para Ortega, ese marco y esa base hay que buscarlos en "la vida personal como realidad radical, la vida como circunstancia y acontecimiento y la indigencia de la realidad humana como modo de ser" (Parra, 2015, 226-227).

${ }^{28}$ En La Idea del hombre, primera versión, Nicol distinguía tres significados en el término "idea": noción no elaborada rigurosamente, concepto riguroso e idea en sentido griego, es decir, forma y realidad al mismo tiempo (1946, 9-10). En Crítica de la razón simbólica destaca, en cambio, dos significados, el de idea y el de ideal: la ideas del hombre como "arquetipos en que las posibilidades existenciales adquieren figura de aspiraciones definidas" (1982, 108).
} 
En estas primeras dos etapas de la historia de la filosofía en Hispanoamérica, la filosofía es ejercida como ideología y no como ciencia, porque el pensamiento de los hispanoamericanos se vuelca sobre su propio ser comunitario, el de sus naciones y el de la región: sobre el ethos de la Independencia y el de la Revolución, no sobre el ethos del hombre sin más. La tesis de Nicol, sin embargo, es que la época anterior, la colonial, principalmente a través de la filosofía escolástica, había ya formado la mente de los hispanoamericanos en el cultivo de la filosofía como ciencia, en su más estricto sentido de cuidado por el ser, rigor metódico y universalidad, y que esa formación previa daba a los hispanoamericanos la oportunidad de tomar su pensamiento ideológico, es decir, sus reflexiones acerca del ethos de la Independencia y el ethos de la Revolución, como punto de partida para reasumir el ejercicio de la filosofía estrictamente científica (cfr. ibid., 61-66).

Tal oportunidad cobra especial relevancia en la época que Nicol escribe $E l$ problema de la filosofía hispánica. Según la interpretación de este filósofo, la tercera etapa de la filosofía en Hispanoamérica, en contraste con las anteriores, estaba marcada por el cultivo cada vez más amplio de la filosofía científica (cfr. ibid., 110-119).

En España observa Nicol un proceso similar al de Hispanoamérica (cfr. ibid., 120-155). ${ }^{29}$ La primera parte del siglo XX, a juicio de este filósofo, presenta en este país unas notas que están presentes de manera destacada en el magisterio y la obra de Ortega y Gasset. Por ello a esa época la llama Nicol "etapa orteguiana”. Se trata de una época en la que prevalece un cierto "ensimismamiento", una meditación centrada en el propio ser. Pero ya en la evolución de las ideas del mismo Ortega percibe Nicol la conciencia de que era necesario efectuar un tránsito al ejercicio de la filosofía científica (cfr. ibid., 142).

Esto nos lleva a las partes segunda y tercera del El problema de la filosofía hispánica. En la segunda Nicol hace una caracterización de la "escuela de Barcelona", por analogía con la "escuela de Madrid", aunque sin considerar a la de Barcelona como una escuela en sentido estricto (con unidad cronológica, de magisterio y de doctrina), sino como un estilo o carácter, una afinidad en la "manera de ver las cosas" (cfr. ibíd. 171-207). En la tercera este filósofo desarrolla

\footnotetext{
${ }^{29}$ Nicol considera a Hispanoamérica y España como integrantes de una misma comunidad histórica y cultural. El fundamento de tal comunidad, aquello que le otorga su carácter unitario, es la hispanidad. Vid. Al respecto Sánchez Cuervo, 2010. Para la visión de Nicol sobre el "ensimismamiento" y el circunstancialismo en la filosofía espańola, vid. Savignano, 1998.
} 
la idea de que el ensayo, género intermedio entre literatura y filosofía, si bien es adecuado para una "meditación del propio ser" o para un pensamiento ensimismado (y de ahí la preferencia de los españoles e hispanoamericanos por este género durante la etapa orteguiana y las primeras dos etapas de la historia de la filosofía en Hispanoamérica), en cambio para la filosofía científica — que exige método, sistematicidad y universalidad- el ensayo no puede sino evidenciar sus propias limitaciones e insuficiencias (cfr. ibid. 211-278). En la segunda y en la tercera parte del libro, como se ve, Nicol continúa desarrollando una forma ideológica de pensar, pues aún restringe su meditación al ámbito hispánico.

Hasta aquí he explicado algunas ideas representativas de El problema de la filosofía hispánica, destacando las características básicas que distinguen en este libro la ideología y la ciencia. Con base en esto y el lo dicho en la sección anterior, desarrollaré la tesis de la complementariedad entre ciencia e ideología en el marco del pensamiento de Nicol.

\section{La complementariedad entre ciencia e ideología}

Conforme al planteamiento de Nicol, ciencia e ideología son, ambas, formas de conocimiento; por tanto, cabe la posibilidad de que las afirmaciones de una sean compatibles con las de la otra. Ciencia e ideología no son necesariamente contradictorias, en el sentido de que lo que afirma una implique forzosamente la negación de lo que afirma la otra.

La compatibilidad entre ciencia e ideología se hace efectiva cuando la ideología utiliza los conocimientos científicos (además de cuando la verdad de lo universal se confirma en la verdad de lo particular, como ya mencioné). La diferenciación fundamental entre ciencia e ideología, y en general entre episteme y doxa, permanece aun cuando las verdades de una y otra se conjuntan coherentemente en un mismo discurso, pues tal diferenciación se deriva de su origen, de la distintiva disposición de cuidado del ser que está a la base de la ciencia.

Pero además de esa compatibilidad, algunas ideas fundamentales que Nicol plantea en el marco de su filosofía científica y las expresadas en El problema de la filosofía hispánica, nos llevan a concluir — extrayendo de ellas una consecuencia implícita- que ciencia e ideología pueden ser en ciertos casos incluso complementarias. Tales ideas son las siguientes: 
Primera idea. En la epistemología de Nicol, la ciencia es un todo al que presta unidad su fundamento: la disposición o cuidado del ser. ${ }^{30}$ Como parte de ese todo, se distinguen unas ciencias particulares o segundas y la ciencia universal o primera. Las particulares se diversifican por su objeto, pues a cada orden y nivel de realidad corresponden principios, conceptos y métodos distintos. ${ }^{31}$ La ciencia universal, que es la metafísica, tiene en cambio por objeto el todo de la realidad y del conocimiento, y no solo uno de sus órdenes o niveles. La metafísica, pues, es necesariamente científica, así como la ciencia necesita a la metafísica para conocer sus propios fundamentos ontológicos y epistemológicos. Ahora bien, el conocer específico de la metafísica es la forma científica de la autoconciencia en el nivel de los principios del ser y del conocer: por la metafísica el sujeto conoce algo de sí, esto es, el fundamento de su conocer, y el particular orden y nivel de realidad de su ser en el marco de la realidad en su conjunto: "en la filosofía culmina la auto-conciencia" (Nicol, 1982, 113). ${ }^{32}$

Segunda idea. En la ontología de Nicol, la radical historicidad del ser del hombre se deriva de su radical expresividad, pues "la expresión es esencialmente diferenciante" (Nicol, 1974, 195). ${ }^{33}$ Esto quiere decir que, si expresar implica interpretar, si expresar un ser manifiesto trae consigo el establecimiento de una malla de relaciones entre ése y otros seres, entonces no puede haber dos expresiones idénticas: no sólo en cuanto todos los elementos de la expresión cambian a través del tiempo (sujeto, objeto, interlocutor, sistema simbólico), sino sobre todo por cuanto cada nueva interpretación agrega al menos una interpretación adicional a las anteriores, a saber, la relación entre aquélla y éstas. Esto es a lo que Nicol se refiere cuando escribe que "la expresión expresa el cambio y a la vez lo produce" (ibid. 197), y en general, cuando vincula los conceptos de historicidad, expresividad y diálogo.

\footnotetext{
${ }^{30}$ Para el tema de la unidad de la ciencia y la relación entre ciencia primera y ciencias particulares, vid. Nicol, Los principios de la ciencia, 1965, 80-89, e Ideas de vario linaje, 1990, 23-37.

${ }^{31}$ Ejemplo: El principio ontológico de la realidad humana es la libertad, y por ello tal realidad ha de ser distintivamente estudiada mediante un método hermenéutico e histórico, y a través de conceptos apropiados, como el de comunidad. Cfr. Nicol, Metafísica de la expresión (primera versión), 1957, 321-346; 1965, 277-293; Metafisica de la expresión (segunda versión), 1974, 189-198, 205-224; El porvenir de la filosofía, 1972, 53-63.

32 Para Nicol, el conocimiento científico de los principios es una forma de autoconciencia; $c f r$. Nicol, Crítica de la razón simbólica, 1982, 110-116, 132-139.

${ }^{33}$ Nicol desarrolla el vínculo entre expresividad, interpretación, diálogo e historicidad, en Nicol, 1957, 297-313, 334-346; 1974, 189-198, 217-224.
} 
Tercera idea. Según Nicol, la ideología posee dos características, el interés y la particularidad de su objeto, y como muestra este mismo filósofo en El problema de la filosofía hispánica, la primera explica la segunda: el interés del sujeto dirige el pensamiento de éste hacia un objeto particular y concreto (así la comunidad hispánica en el caso de dicho libro), un objeto localizado a través de precisas coordenadas históricas, culturales, sociales, etc.

La consecuencia implícita en la conexión de estas tres ideas, es decir, la complementariedad de ciencia e ideología, se enmarca en la tarea del hombre de conocerse a sí mismo. Pues si a la ciencia le atańe la autoconciencia del sujeto en el nivel de lo universal, si el hombre ha de ser conocido no sólo en lo universal sino también en su concreta historicidad, y si a la ideología le corresponde el conocimiento del hombre en el nivel de lo particular, entonces la autoconciencia del hombre, su autognosis, autocomprensión o autoconocimiento, sólo puede completarse mediante la complementación de ciencia e ideología. "Los individuos humanos no pueden considerarse como simples casos particulares de un género común; sería ilegítimo desde el punto de vista fenomenológico, prescindir de las diferencias, o conceptuarlas como meramente accidentales, porque esas diferencias, constitutivas de la singularidad óntica, son la manifestación actual de la forma común" (Nicol, 1974, 195). El conocimiento del hombre, que la metafísica realiza en el nivel de una ontología desinteresada y universal, se completa con el conocimiento que del hombre concreto y particular opera la ideología gracias al interés y no a pesar del mismo. El conocimiento del hombre sin más y el conocimiento del hombre situado (el español, el hispanoamericano, etc.), si bien tienen su origen en disposiciones distintas hacia el ser, conducen no obstante al mismo destino: el autoconocimiento del hombre.

Por supuesto: no toda ideología es compatible o complementaria con la ciencia. La ideología, asentada en el interés, puede llegar a deformar o incluso falsear el conocimiento científico que utiliza, y hacerlo precisamente a causa de ese interés. Por ello, cuando Nicol afirma que en El problema de la filosofía hispánica sus opiniones tienen carácter ideológico, de inmediato aclara que su philia por los países de la comunidad hispánica no impide que esas mismas opiniones sean inspiradas por la philía de la verdad (cfr. Nicol, 1998, 45-46).

Quiere esto decir que el planteamiento de Nicol da lugar para una forma de conocimiento que, incluso siendo ideológico y por tanto carente de desinterés y universalidad, adopta una disposición semejante a la del cuidado del ser; pues la philía de la verdad, si bien se realiza eminentemente en la ciencia (con su 
consiguiente expresión en la búsqueda de universalidad), también está presente en el conocimiento precientífico.

Philía y pensamiento ideológico: su relación se aclara si consideramos dos descripciones que desarrolla Nicol en su metafísica, la de la ciencia como vocación, y la de la ejemplaridad como aporte de toda vocación a su comunidad. ${ }^{34}$

Recordemos que en su ontología este filósofo hace la distinción entre una praxis práctica y una "praxis im-práctica". Esta última se ramifica en tres formas de expresión, la mística, la estética y la científica, que corresponden a disposiciones radicales del hombre ante el ser ( $c f r$. Nicol, 1978, 63). Tales disposiciones pueden adoptarse de manera situacional, pero sólo constituyen vocaciones cuando se presentan como una preferencia sistemática (cfr. Nicol, 1974, 250). $\mathrm{El}$ recurso circunstancial no basta para que el cuidado ante el ser se realice como vocación, como ciencia, sino que es necesario situar ese cuidado en el centro de los afanes vitales; pues hay vocaciones profesionales cuyo ejercicio "es tan radical y tan amplio que no deja espacio para otros ejercicios marginales, o los cualifica, en todo caso, y los hace dependientes del menester principal [...] Tal es la vocación del filósofo, y por esto es la filosofía una forma de vida [...]" (Nicol, 1997, 21).

Pues bien, las vocaciones, como formas de "praxis im-práctica", no son por principio y origen útiles a su comunidad. Es decir: la disposición fundamental que las genera y fundamenta, no corresponde al interés, aunque los resultados de su actividad puedan en una u otra circunstancia ser utilizados para necesidades o problemas específicos. Pero a pesar de que en sí mismas y por sí mismas no son útiles, las vocaciones prestan un servicio a la comunidad. Ese servicio consiste en su ejemplaridad:

\footnotetext{
${ }^{34} \mathrm{El}$ tema de las vocaciones y el de la ejemplaridad vocacional pueden seguirse principalmente en los siguientes textos de Nicol: La vocación humana (1a ed.), 1953, "Expresar para ser" y "La vocación humana", 9-21, 25-45; Metafisica de la expresión (primera versión), 1957, "La forma vocacional del ser", 313-320, y los parágrafos 40 y 41; Los principios de la ciencia, 1965, 277-293; El porvenir de la filosofia, 1972, 35-44; Metafísica de la expresión (segunda versión), 1974, 199-204, 249-257; La reforma de la filosofia, 1980, 114-217; Crítica de la razón simbólica, 1982, 140-150; Ideas de vario linaje, 1990, 281-298; La vocación humana (2a ed.), 1997, 19-32, 35-57. Vid., al respecto, Beltrán, 2017. El tema complementario, el del ocaso de las vocaciones libres en nuestra época, es estudiado por Aguirre y Yahair (2017), enlazando el concepto nicoliano de razón de fuerza mayor, con el de un totalitarismo que trasciende el ámbito de la política, el totalitarismo como disposición del hombre ante el mundo, ante el otro hombre y ante sí mismo.
} 
Pues ¿qué es "lo que da de sî" la filosofía? La philosophia da razón, lo mismo en el nivel de la filosofía estricta, que en el nivel de la ciencias particulares. Da razón y nada más. Si nos habituamos a distinguir desde ahora entre utilidad y servicio, veremos que el servicio de la razón entraña un ofrecimiento mayor que el de unos pensamientos [...] Producir un pensamiento libre, o mejor dicho, producir un hombre liberado por el pensamiento: éste es el ofrecimiento de la filosofía a la humanidad (Nicol, 1972, 23). ${ }^{35}$

Las vocaciones muestran a su comunidad los caminos por los cuales al hombre le es dado realizarse como ser libre, como ser humano: humanizarse. El científico, a través de su ejemplo, mantiene viva en su comunidad la conciencia de que entre las potencias del hombre está la de adoptar ante el ser una disposición de cuidado, y su comunidad puede seguir ese ejemplo realizando tal disposición, situacional o sistemáticamente, pero en todo caso imprimiendo a su vida - a través del cuidado del ser- una forma propiamente humana, la forma de la libertad: "La ciencia es el compromiso vocacional, libremente elegido, de vivir diciendo cómo son las cosas en sí mismas [...] ofrece a todos la ejemplaridad de la verdad" (Nicol, 1974, 160).

Por supuesto, la philía de la verdad no puede ser otra cosa que un cuidado del ser, un afán por desembarazar al ser de la capa de prejuicios, errores e intereses que el sujeto proyecta sobre el ser en el conocimiento precientífico. Pero en la epistemología de Nicol el término "cuidado del ser" está vinculado a la ciencia, y por tanto, implica como nota básica un objeto universal y no particular. Por otra parte, es indudable que la ejemplaridad de la ciencia induce en el conocimiento precientífico una disposición semejante al cuidado del ser, una philía de la verdad que no adopta la forma de preferencia sistemática o vocación, sino que se presenta de manera circunstancial. Tales consideraciones exigen distinguir esa philía compatible con un pensamiento ideológico, y el cuidado que la ciencia despliega sistemáticamente por el ser.

El problema de la filosofía hispánica es, precisamente, muestra de convergencia entre pensamiento ideológico explícito y philía de la verdad.

\footnotetext{
${ }^{35}$ En esta cita he corregido dos erratas evidentes: mientras que el original dice "de razón" y "dar razón", en ambos casos transcribo "da razón". La modificación de la forma no afecta el contenido.
} 
Entendida de este modo, la concepción que Nicol plantea de la ideología resulta contrastante con la de un filósofo como Luis Villoro, para quien la ideología consiste en un conjunto de creencias que (primer criterio) no están suficientemente justificadas, y que (segundo criterio) promueven el poder político de un grupo social (cfr. Villoro, 2007, "Del concepto de ideología", 15-37). ${ }^{36}$ Conforme a Villoro, la falta de una justificación suficiente y el interés político distinguen a la ideología respecto al conocimiento en general, incluida en éste la ciencia. En cambio, en Nicol la ideología sí constituye conocimiento, y específicamente una forma de conocimiento precientífico, de doxa; puede estar justificada, debido a su philía por la verdad; y no necesariamente responde a un interés político. ${ }^{37}$

Para diferenciar concepciones como la de Villoro (en las que la ideología se caracteriza por su justificación insuficiente y por su sesgo político) respecto a la de Nicol (en la cual lo propio de la ideología no radica en su grado de justificación ni en su orientación política sino, fundamentalmente, en la particularidad de su objeto, determinada por el interés o la "philía"), en vez de utilizar el término "ideología" podemos hablar de "autocomprensión histórica".

No es, esta última, sino una simple propuesta terminológica, pero que puede tener un efecto apreciable en la recepción de las ideas que Nicol expone en $E l$ problema de la filosofía hispánica. Al declarar este libro como una muestra de pensamiento ideológico, puede entenderse que, en el mismo, Nicol suprime la philía de la verdad, y que en el lugar de ésta coloca el interés político. Nada más lejos de la verdad. Como filósofo íntegro, Nicol consiente que el interés limite su objeto de estudio a la particularidad de una determinada comunidad cultural e

\footnotetext{
${ }^{36}$ Villoro entiende la "justificación suficiente" en el sentido de "garantía de la verdad" ( $c f r$. Villoro, 1989, 178-186). Según este filósofo, la voluntad interfiere con el proceso de deliberación, y por tanto produce distorsiones, de tres formas: incitando parcialmente a la crítica o a la búsqueda de razones a favor; otorgando mayor peso a unas razones y desestimando otras; acelerando, retardando o interrumpiendo el proceso (ibid. 102-125); así en la ideología. En cambio, como ya vimos, para Nicol la ideología, si bien puede caer en tal interferencia, también puede evitarla gracias a la philía de la verdad.

${ }^{37} \mathrm{Al}$ reflexionar sobre la relación de los países de la comunidad hispánica con las grandes potencias de nuestro tiempo, Nicol escribe: "Nuestra misión es convertirnos en la conciencia del poder [...] La opinión es logos, el buen ejemplo es ethos. Éstas son nuestras armas, no tenemos otras. Pero éstas bastan" (Nicol, El problema de la filosofía hispánica, 1998, 162). No se trata de promover un poder político, se trata de contribuir a la humanización del hombre, comenzando por el hombre concreto, particular, el de nuestra propia comunidad.
} 
histórica con la cual se siente identificado, a la cual se "afilia", pero nunca permite que ese interés suplante a la philía de la verdad.

\section{Conclusiones}

La explicitación de la complementariedad entre ciencia e ideología es, primeramente, un aporte a la interpretación del pensamiento de un filósofo importante en la historia de la filosofía hispanoamericana, Eduardo Nicol.

Pero, más allá de la exégesis de un determinado pensador, tal explicitación tiende puentes entre formas discrepantes de concebir a la filosofía.

En efecto: Nicol nos muestra que la ideología no puede ser ciencia, y que la ciencia no puede ser ideología, pero también nos hace ver que una y otra son formas legítimas del pensamiento filosófico. Ello explica que él mismo se haya permitido escribir un libro de contenido ideológico, El problema de la filosofía hispánica.

En tal obra, adicionalmente, este filósofo nos conduce a la comprensión de que, siendo el hombre radicalmente histórico, el autoconocimiento del mismo no se agota en el nivel desinteresado y universal de la ciencia, sino que exige adoptar, de forma complementaria, un nivel de interés o philía y de particularidad en el objeto de estudio.

Pero, como hemos visto, no todo pensamiento ideológico sirve a la tarea de autoconocimiento del hombre.

Mi lectura de Nicol muestra que la ideología, a pesar de asentarse en el interés (o en la philía hacia la propia comunidad), y no obstante la particularidad de su objeto, tiene entre sus posibilidades la philía de la verdad. Esta philía es lo que hace apto al pensamiento ideológico para un verdadero autoconocimiento.

Así se explica cómo un pensamiento como el latinoamericanista, el de la filosofía de la liberación o el marxista —-mencionados al principio de este artículo-, pueden estar orientados desde su base por el compromiso con una determinada comunidad histórica y cultural, y a la vez ser fieles a la verdad. Su compromiso no implica de modo necesario el falseamiento o la distorsión de los conocimientos científicos de los que hacen uso. 
Con esto se abren las puertas al diálogo entre quienes conciben a la filosofía al modo de Nicol, como ciencia universal, y quienes la entienden como respuesta a las concretas necesidades y los particulares problemas de la propia comunidad.

\section{Referencias}

Aguirre M., Arturo y Yahair B. G., Eduardo (2017). "Eduardo Nicol: el totalitarismo y el régimen de fuerza mayor en la vida. El mundo ante la violencia total", Bajo palabra. Revista de Filosofía, núm. 13, pp. 121-133.

Beltrán G., Iver A. (2017). "Diálogo, comunidad, historia. La teoría de las vocaciones en la metafísica de Eduardo Nicol", Comprendre. Revista catalana de filosofia, vol. 19, núm. 1, pp. 19-37.

CoRTÉs, Francisco J. (2014). "La fenomenología dialéctica de Eduardo Nicol", Investigaciones fenomenológicas, núm. 11, pp. 57-79.

GonzÁlez, Roberto A. (2014). "Metafísica y contradiscurso del método: Hacia una nueva concepción del ser a partir de la óptica de Eduardo Nicol", Revista de filosofia, vol. 39, núm. 1, pp. 29-45.

-(2017). "José Gaos y Eduardo Nicol: Contraste entre dos ideas de la filosofía", Signos Filosóficos, vol. XIX, núm. 38, pp. 150-175.

GonZÁlez, Rush (2007). "Estructura, historia y unidad de la ciencia a partir de la óptica de Eduardo Nicol”, Ciencia Ergo Sum, vol. 14, núm. 2, pp. 208-216.

GonZÁlez VAlenzuela, Juliana (2009a). "La ciencia-filosofía en Eduardo Nicol", Theoría. Revista del Colegio de Filosofía, núm. 19, pp. 13-26.

-(2009b). "La revolución en la metafísica: Heráclito y Nicol", en Horneffer, Ricardo. Eduardo Nicol (1907-2007). Homenaje. México: UNAM.

González Valenzuela, Juliana \& Sagols Sales, Lizbeth (2002). El ethos del filósofo. México: UNAM.

Horneffer, Ricardo (2009). Eduardo Nicol (1907-2007). Homenaje. México: UNAM.

-(2013). El problema del ser: sus aporías en la obra de Eduardo Nicol. México: UNAM.

Nicol, Eduardo (1941). Psicología de las situaciones vitales. México: El Colegio de México.

-(1946). La idea del hombre. México: Stylo. 
-(1950). Historicismo y existencialismo. La temporalidad del ser y la razón. México: El Colegio de México.

-(1953). La vocación humana. México: El Colegio de México.

-(1957). Metafísica de la expresión. México: FCE.

-(1961). El problema de la filosofía hispánica. Madrid: Tecnos.

-(1963). Psicología de las situaciones vitales. 2a ed. México: FCE.

-(1965). Los principios de la ciencia. México: FCE.

-(1972). El porvenir de la filosofía. México: FCE.

-(1974). Metafísica de la expresión. 2a ed. México: FCE.

-(1977). La idea del hombre. México: FCE.

-(1978). La primera teoría de la praxis. México: UNAM.

-(1980). La reforma de la filosofía. México: FCE.

-(1982). Crítica de la razón simbólica. La revolución en la filosofía. México: FCE.

-(1990). Ideas de vario linaje. México: UNAM.

-(1997). La vocación humana. 2a ed. México: FCE.

-(1998). El problema de la filosofía hispánica. 2a ed. México: FCE.

-(2004). La agonía de Proteo. México: UNAM-Herder.

Parra Ferreras, José Antonio (2015). "Ética vital en Ortega y Gasset. Reflexiones sobre su fundamentación”, Éndoxa: Series filosóficas, núm. 36, pp. 213-250.

SÁnchez Cuervo, Antolín (2010). "Lecturas de la Independencia en el exilio español del 39. José Gaos, Joaquín Xirau y Eduardo Nicol", Theoría. Revista del Colegio de Filosofía, núm. 22, pp. 97-118.

SÁnchez VÁzquez, Adolfo (2003a). Filosofía de la praxis. México: Siglo XXI.

-(2003b). "Filosofía, ideología y sociedad", en Ibid., A tiempo y destiempo. Antología de ensayos. México: FCE, pp. 254-279.

Savignano, Armando (1998). "El problema de la filosofía española", Revista Anthropos. Huellas del conocimiento, núm. extraordinario 3, pp. 158-162.

Villoro, Luis (1989). Creer, saber, conocer. 2a ed. México, Siglo XXI. 
-(1995). En México, entre libros. México: El Colegio Nacional-FCE.

-(2007). El concepto de ideología y otros ensayos. México: FCE.

Zirión, Antonio (2004). Historia de la fenomenología en México. Morelia (México): Jitanjáfora.

Recibido : 08/05/2016

Aceptado : 20/04/2017

\section{(ब)}

ENDOXA está bajo una licencia de Creative Commons Reconocimiento-NoComercial-SinObraDerivada 4.0 Internacional 
